\title{
Antecedentes de Comportamentos de Busca de Emprego na Transição da Universidade para o Mercado de Trabalho
}

\author{
Mauro de Oliveira Magalhães ${ }^{1}$ \\ Universidade Federal da Bahia \\ Marco Antonio Pereira Teixeira \\ Universidade Federal do Rio Grande do Sul
}

\begin{abstract}
RESUMO - Esta pesquisa investigou variáveis pessoais e situacionais relacionadas a comportamentos de busca de emprego. Participaram 253 universitários ao final da graduação, que responderam a escalas de lócus de controle, autoeficácia, apoio social, independência e motivação nas transições de carreira, além de medidas de necessidade financeira, valores de carreira, avaliação pessoal do mercado de trabalho e de comportamentos de busca de emprego. Análises de regressão indicaram que lócus de controle, apoio social e necessidade financeira foram os melhores preditores desses comportamentos. Indivíduos que priorizaram a estabilidade no emprego apresentaram maior necessidade financeira, externalidade de controle e maior frequência de busca de emprego. Implicações teóricas e práticas dos resultados são discutidas.
\end{abstract}

Palavras-chave: busca de emprego, desenvolvimento de carreira, estudantes universitários

\section{Antecedents of Job-Search Behavior in the Transition from University to Labor Market}

\begin{abstract}
This study investigated personal and situational variables related to job-search behaviors. Participants were 253 college students at the end of their undergraduate courses. Respondents completed scales of locus of control, self-efficacy, social support, independence, and motivation in career transitions, as well as measures of financial need, career values, personal evaluation of the labor market and job-search behaviors. Regression analysis showed that locus of control, social support and financial need were predictors of job-search behaviors. Individuals who valued job tenure as a top career value exhibited greater levels of financial need, external locus of control, and job-search behavior. Theoretical and practical implications of these results are discussed.
\end{abstract}

Keywords: job search, career development, college students

A busca de emprego é um tópico de importância para pesquisadores e profissionais que assistem indivíduos no alcance de metas de vida e trabalho. O tema é relevante para muitas pessoas, especialmente para trabalhadores desempregados, para os que estão entrando no mercado de trabalho pela primeira vez, e aqueles que desejam mudar de emprego ou carreira.

O foco do presente estudo é o processo de busca de emprego em estudantes do último período de graduação universitária. Considera-se que os concluintes do ensino superior estão vivenciando um processo de transição de carreira, do ambiente universitário e do papel de estudante para o mercado de trabalho e o papel profissional. E que essa transição exige desses indivíduos a mobilização de seus recursos pessoais de adaptabilidade a novas situações e papéis. Nem todos se sentem preparados para enfrentar a complexidade desse processo, que coloca em cheque sentimentos de competência pessoal e desafia a viabilidade concreta de projetos de carreira. Para muitos desses jovens profissionais, uma das tarefas cruciais da transição para o mercado de trabalho é a busca de emprego.

1 Bolsista da Capes - Proc. : BEX: 8732-11-6

Endereço para correspondência: Instituto de Psicologia, Rua Aristides

Novis, 2 - Estrada de São Lázaro. Salvador, BA. CEP 40210-730.

Email: mauro.m@terra.com
É crescente o número de pesquisas sobre busca de emprego nas últimas décadas, e observam-se duas linhas de pesquisa principais: a) investigação dos preditores e resultados da busca de emprego (e.g., Chen \& Lim, 2012; Sacks, 2005; Wanberg, Kanfer, \& Banas, 2000; Wanberg, Hough, \& Song, 2002); e b) teste de intervenções para ajudar buscadores de emprego a realizar seus objetivos (e.g., Vinokur $\&$ Schul, 2002). É evidente que achados das pesquisas sobre preditores e resultados da busca de emprego devem subsidiar o desenvolvimento de intervenções, porém esta conexão tem sido insuficiente (Chen \& Lim, 2012; Sacks, 2005). Diante da escassez de estudos nacionais sobre o tema, a presente pesquisa investigou aspectos disposicionais e contextuais considerados preditores de comportamentos de busca de emprego em estudos internacionais, a fim de examinar a adequação dos mesmos em amostras brasileiras e oferecer subsídios para o delineamento de programas de preparação de universitários para a entrada no mercado de trabalho.

Inúmeros fatores disposicionais e situacionais têm sido associados a comportamentos de busca de emprego. Entre as variáveis psicológicas ou de personalidade, a autoestima, os traços de extroversão e realização (modelo dos Cinco Grandes Fatores) (Kanfer, Wanberg, \& Kantrowitz, 2001), a autoeficácia para busca de emprego (Zikic \& Saks, 2009), o controle situacional percebido (Kanfer et al., 2001), a 
percepção de empregabilidade (Chen \& Lim, 2012) e o comprometimento do indivíduo com o papel de trabalhador (Wanberg, Kanfer, \& Rotundo, 1999) se mostraram preditores de comportamentos de busca de emprego. Wanberg, Hough e Song (2002) se referiram a essas variáveis como o potencial humano do buscador de emprego, definido como a capacidade, experiência, personalidade e outras características de diferença individual.

Chen e Lim (2012), a partir do esquema teórico de Luthans, Youssef e Avolio (2007), defendem que quatro fatores disposicionais são especialmente importantes para o sucesso da busca de emprego: autoeficácia, expectativa ou "esperança", resiliência e otimismo. Os autores observaram que indivíduos com escores elevados em medidas psicológicas desses fatores informaram maior percepção de empregabilidade e adotaram estratégias de coping mais diversificadas e eficientes para lidar com essa transição em suas carreiras. Nos resultados de sua pesquisa, a percepção de ser empregável se revelou um aspecto motivacional importante para a busca de emprego (Chen \& Lim, 2012). A percepção de empregabilidade e os próprios comportamentos de busca de emprego podem estar associados, também, a um lócus de controle interno, ou seja, à crença de que o sucesso em determinadas tarefas ou a ocorrência de certos eventos depende mais dos esforços individuais do que fatores externos (Pasquali, Alves, \& Pereira, 1998). Embora essa seja uma expectativa teoricamente razoável, as evidências empíricas não mostram uma relação substancial de internalidade com busca de emprego, e até mesmo tem-se verificado a existência de uma relação inversa (van Hooft \& Crossley, 2008).

Enfim, a pesquisa sobre diferenças individuais associadas à busca de emprego ainda é um campo a ser mais bem explorado (Saks, 2005). A complexidade do tema se revela, por exemplo, no alerta de Luthans et al. (2007) sobre a possibilidade de que uma excessiva crença de autoeficácia e/ ou otimismo possa resultar em expectativas irrealistas e no investimento de energia em metas dificilmente alcançáveis. Buscadores de emprego podem construir avaliações equivocadas sobre sua real empregabilidade e assim sofrerem decepções que resultam em prejuízo importante as suas atividades de busca de emprego subsequentes. Sobre esses aspectos, Heppner, Multon e Johnston (1994) destacaram a importância de cognições realistas sobre si mesmo, sobre as ocupações e sobre processos de transição de carreira.

Os comportamentos de carreira precisam ser contextualizados em termos das condições ambientais e situacionais que afetam o indivíduo. Entre os preditores situacionais da busca de emprego, a presença de apoio social tem se revelado um dos fatores mais importantes (Kanfer et al., 2001; Slebarska, Moser, \& Gunnesch-Luca, 2009). O apoio social se refere à rede de amigos e familiares que provêm aconselhamento, assistência e encorajamento aos sujeitos. O apoio de outras pessoas na busca de emprego possui um papel crucial no fortalecimento da autoestima e motivação (Slebarska et al., 2009; Wanberg, Watt, \& Rumsey, 1996). Na meta-análise de Kanfer et al. (2001), o apoio social foi positivamente associado com intensidade de busca de emprego, sendo esta relação mais acentuada para aqueles que perderam o emprego do que para quem está entrando no mercado de trabalho. Por outro lado, Heppner et al. (1994) observaram que, embora relações interpessoais de intimidade e confiança possam ser encorajadoras para o enfrentamento de transições, também podem ser problemáticas quando a consideração das necessidades de pessoas próximas é incompatível com a realização de interesses ou valores pessoais.

Além do apoio social, a variável percepção de necessidade financeira tem se mostrado um forte preditor situacional de comportamentos de busca de emprego (Šverko, Galić, Seršić, \& Galešić, 2008; van Hoof \& Crossley, 2008). A premissa básica relativa a esse preditor é que indivíduos que possuem obrigações financeiras importantes ou que carecem de recursos financeiros adequados apresentam maior necessidade e tendência para conduzir uma busca de emprego intensiva (Šverko et Al., 2008; Wanberg, Kanfer, \& Rotundo, 1999).

No caso de estudantes universitários concluintes, as condições do mercado de trabalho em cada área de carreira também devem ser levadas em consideração. As pesquisas de Neiva (1993, 1995, 1996) e Teixeira (2002) examinaram os efeitos da avaliação subjetiva do mercado de trabalho sobre os projetos de carreira de estudantes finalistas. A pesquisa de Neiva (1996) apontou que estudantes que se preparavam para ingressar em mercados percebidos como ruins estimaram menos ofertas de emprego e menores chances de realizarem seus projetos de carreira em comparação àqueles que percebiam o mercado de trabalho como mais promissor. A percepção desfavorável do mercado de trabalho também foi associada a menor motivação e maior ansiedade (Neiva, 1993, 1995). Por outro lado, contrariando expectativas, estudantes em carreiras de mercado percebidos como ruins estimaram menor tempo para o início da atividade profissional e mostraram-se mais decididos quanto a seus projetos de carreira (Neiva, 1996). A autora sugeriu que a percepção negativa do mercado de trabalho pode acelerar decisões e planos de carreira.

No estudo de Teixeira (2002), formandos que enfrentavam mercados mais restritos se perceberam mais carentes de redes de apoio (contatos sociais e profissionais), de estratégias de busca de emprego e de conhecimento sobre oportunidades de carreira. $\mathrm{O}$ autor sugeriu que esse resultado é decorrente de uma maior sensibilização desses estudantes para os recursos necessários para uma transição bem-sucedida, o que não seria tão nítido e relevante para formandos de áreas profissionais com mercado mais favorável, uma vez que estes últimos acreditam que obterão trabalho sem grandes dificuldades. Por fim, corroborando estudos internacionais (Albert \& Luzzo, 1999; Lent, Brown, \& Hackett, 2000), Teixeira (2002) considerou que comportamentos de carreira dependem mais da forma como o indivíduo percebe o mercado de trabalho do que propriamente das suas condições objetivas.

A partir da revisão da literatura, acredita-se que percepções mais ou menos favoráveis sobre o mercado de trabalho podem afetar níveis de motivação, controle percebido e crenças de autoeficácia para uma transição bem sucedida. Além disto, é razoável supor que o grau de pressão financeira e a avaliação do mercado de trabalho influenciem as estratégias e as prioridades do processo de busca de emprego. 
Nesse sentido, Peres, Silva e Carvalho (2003) investigaram o perfil dos desempregados e as vagas de trabalho disponibilizadas pelo mercado na cidade de Assis (SP) e região. Os autores constataram que os cargos mais procurados pelos sujeitos requeriam pouca escolaridade e qualificação. A procura por essas alternativas de emprego foi atribuída à urgência do desempregado por encontrar algo que lhe garanta a subsistência, aceitando, portanto, qualquer alternativa que o retire de sua condição econômica improdutiva o mais rápido possível. Sendo assim, observa-se que a pressão econômica pode levar os indivíduos a aceitar opções de carreira que não estejam associadas às suas preferências e características pessoais. Portanto, as atividades de busca de emprego podem ser guiadas por prioridades diversas. Enquanto alguns indivíduos podem estar preocupados com realização pessoal no trabalho e vislumbram horizontes de carreira em longo prazo, outros podem estar em busca de um meio de subsistência em curto prazo. Essas prioridades também podem ser denominadas de valores de carreira que, tal como exemplificado acima, podem ser situacionais/periféricos ou centrais. Valores periféricos respondem a necessidades de ajustamentos imediatos e circunstanciais; e os valores centrais constituem o sistema de valores individual adquirido durante a socialização primária. Pesquisas revelaram que valores centrais dificilmente mudam, enquanto os valores periféricos tendem a mudar com mais facilidade, uma vez que são afetados por pressões ambientais e situacionais (Sharabi \& Harpaz, 2009).

A presente pesquisa parte da premissa que os valores ou prioridades de carreira constituem um fator importante para o entendimento de comportamentos de busca de emprego, pois indicam as crenças de cada trabalhador sobre o que seja uma carreira ideal. Desse modo, são expressões do significado pessoal do papel de trabalho e guiam reflexões e decisões relacionadas (Kim, 2005). No extenso estudo internacional conduzido por Super e Šverko (1995), a análise dos dados coletados em 10 países encontrou 18 tipos de orientações de valor com relação ao trabalho, a saber: desenvolvimento pessoal, utilização de habilidades, relacionamento social, realização, estilo de vida, autonomia, estética, altruísmo, criatividade, economia, condições de trabalho, interação social, ascensão, atividade física, variedade, prestígio, risco, e autoridade. A popular taxonomia de âncoras de carreira proposta por Schein (1990) é um exemplo de categorização de estilos de carreira com base em valores. Coetzee e Esterhuizen (2010) observaram que os valores prioritários de graduandos que participavam de um programa de preparação para entrada no mercado de trabalho eram a estabilidade no emprego e ter oportunidades de aperfeiçoamento profissional. Coetzee e Schreuder (2008), num estudo sobre âncoras de carreira de universitários, concluíram que indivíduos em início de carreira tendem a valorizar oportunidades de desenvolvimento e crescimento futuro.

Esta pesquisa investigou as relações entre recursos psicológicos para o enfrentamento de transições de carreira (motivação, autoeficácia, lócus de controle, apoio social percebido e independência de decisão), valores de carreira, necessidade financeira, percepção do mercado de trabalho e intensidade de comportamentos de busca de emprego em estudantes no último semestre da graduação universitária.

\section{Método}

\section{Participantes}

A amostra foi composta por 215 estudantes universitários (58,6\% mulheres), com idades entre 20 e 42 anos, do penúltimo ou último ano de cursos de graduação de duas universidades públicas situadas nas regiões sul e nordeste do Brasil. A distribuição de participantes entre os cursos foi a seguinte: administração $(16,3 \%)$, direito $(11,2 \%)$, comunicação $(10,7 \%)$, secretariado executivo $(8,4 \%)$, engenharia química $(7,9 \%)$, contabilidade $(7,4 \%)$, química $(6,5 \%)$, computação $(5,1 \%)$, economia $(5,1 \%)$, nutrição $(5,1 \%)$ e outros $(16,3 \%)$. Todos informaram ter como objetivo de carreira a obtenção de emprego na sua área profissional após a graduação. No momento da pesquisa os participantes não trabalhavam ou, se tinham trabalho, este não era relacionado à área do curso.

\section{Instrumentos}

Todos os participantes preencheram os seguintes instrumentos: Inventário de Transição de Carreira (ITC) (Heppner et al., 1994); Escala de Intensidade Geral de Busca de Emprego e a Escala de Intensidade de Contatos de Rede Social para Busca de Emprego (Wanberg et al., 2000). Os comportamentos de busca de emprego foram divididos em atividades com e sem contatos de rede social, pois se considera que o uso de contatos de rede social caracteriza uma categoria diferenciada deste tipo de comportamento (Wanberg et al., 2000). Os sujeitos informaram ainda dados demográficos como sexo, idade e estado civil.

O Inventário de Transição de Carreira (ITC) foi desenvolvido por Heppner et al. (1994) para avaliar preditores de sucesso em transições de carreira. O instrumento é constituído por frases que descrevem sentimentos e percepções sobre aspectos da experiência de enfrentar uma transição de carreira. O sujeito marca o quanto as assertivas são verdadeiras para si numa escala do tipo Likert de 1 (totalmente falso) a 5 (totalmente verdadeiro). Os itens agrupam-se em cinco fatores, a saber: motivação, autoeficácia, controle, apoio social percebido e independência de decisão. O fator motivação reflete a avaliação do indivíduo sobre sua disposição para empreender esforços para atingir seus objetivos em uma transição de carreira. A autoeficácia refere-se à percepção da capacidade pessoal para realizar uma transição bem sucedida. $\mathrm{O}$ fator controle, equivalente a lócus de controle, refere-se à percepção do quanto a transição está no controle do indivíduo em oposição a fatores externos como a sorte ou as decisões de outras pessoas. O apoio social percebido reflete o grau em que pessoas significativas apoiam, na percepção do indivíduo, suas decisões de carreira. E o fator independência de decisão revela a percepção do sujeito sobre o quanto suas escolhas estão subordinadas às necessidades e demandas de outras pessoas importantes de suas vidas.

A versão brasileira do instrumento foi elaborada para a presente pesquisa. $\mathrm{O}$ instrumento original com 40 itens, em inglês, foi traduzido para o português, separadamente, por 
dois psicólogos bilíngues. As versões traduzidas foram comparadas e não mostraram diferenças dignas de nota. Alguns itens, contudo, não foram incluídos na aplicação por terem sido julgados inadequados para a população universitária, findando o instrumento com 28 itens. Os dados obtidos com a amostra foram submetidos à análise fatorial exploratória, tendo-se forçado uma solução de cinco fatores conforme a expectativa teórica. Os resultados, de um modo geral, revelaram correspondência satisfatória com o inventário original, com os itens apresentando cargas nos fatores esperados entre 0,38 e 0,76, sem cargas cruzadas importantes. Os índices de consistência interna (alphas de Cronbach) das subescalas do ITC na amostra estudada variaram de 0,68 a 0,71 .

Os comportamentos de busca de emprego foram avaliados pela Escala de Intensidade Geral de Busca de Emprego e pela Escala de Intensidade de Contatos de Rede Social. Essas escalas foram elaboradas por Wanberg et al. (2000) e foram submetidas aos mesmos procedimentos descritos em relação ao Inventário de Transição de Carreira (ITC). A Escala de Intensidade Geral de Busca de Emprego é composta de sete frases que descrevem atividades de busca de emprego sem referência ao uso de redes sociais (exemplo: "enviei meu currículo para empregadores potenciais"). Essa escala obteve índice de consistência interna (alpha de Cronbach) de 0,88. A Escala de Intensidade de Contatos de Rede Social (Networking Intensity no original) é composta de seis frases que descrevem atividades em que as redes de apoio social do indivíduo são utilizadas como recursos para obter informações, indicações e conselhos relacionados à busca de emprego (exemplo: "fiz contato com conhecidos para pedir orientações e conselhos relacionados à minha busca de emprego"). Essa escala obteve índice de consistência interna (alpha de Cronbach) de 0,86. Em ambas as escalas, os sujeitos informam, numa escala do tipo Likert de 1 (nunca - nenhuma vez) a 5 (muito - no mínimo 10 vezes), a frequência dessas atividades nas duas últimas semanas.

A variável necessidade financeira foi mensurada pelo grau de concordância com as frases "a minha condição financeira não me permite ficar muito tempo desempregado" e "tenho urgência para encontrar emprego, pois minhas economias estão se acabando" numa escala Likert de 1 (totalmente falso a meu respeito) a 5 (totalmente verdadeiro a meu respeito). A correlação entre esses dois escores foi $r=0,62(p<0,01)$ e a variável foi definida pela soma dos mesmos.

Cada participante informou sua avaliação particular do mercado de trabalho em sua área profissional, assinalando uma das seguintes categorias (Teixeira, 2002): (1) muito ruim, (2) ruim, (3) razoável tendendo a ruim, (4) razoável tendendo a bom, (5) bom e (6) muito bom.

Para avaliar valores ou prioridades de carreira na transição da universidade para o mercado de trabalho, os participantes foram convidados a hierarquizar em ordem decrescente os cinco valores mais importantes que guiam a sua busca de emprego. O instrumento de pesquisa ofereceu uma lista de 11 valores para serem selecionados e hierarquizados, a saber: aperfeiçoamento de competências, ocupar posições de liderança, ganhos financeiros elevados, segurança/estabilidade, flexibilidade/estilo de vida, ser útil à sociedade, autonomia/independência, criatividade empreendedora, enfrentar desafios, ajudar os outros, e fazer o que mais gosto. Essa lista foi composta a partir da revisão de literatura sobre valores de carreira (Schein, 1990; Super \& Šverko, 1995). Os participantes foram convidados a acrescentar outros valores a essa lista, na falta de um valor considerado importante pelo indivíduo.

\section{Procedimentos}

Os dados foram coletados em sala de aula, em aplicação coletiva, em horário previamente acordado com coordenadores de curso e professores de diversas áreas de duas universidades públicas federais situadas nas regiões sul e nordeste. Aqueles que concordaram em participar assinaram um termo de consentimento livre e esclarecido.

Análises de regressão foram empregadas para investigar a relação entre comportamentos de busca de emprego (tanto intensidade geral quanto intensidade de contatos de rede social, que foram variáveis-critério) e os fatores do ITC e a necessidade financeira (preditores). Previamente às análises, $\mathrm{o}$ banco de dados foi examinado para detectar casos com dados faltantes ou extremos nas variáveis utilizadas nas regressões (escores $z$ superiores a 3 em módulo nas variáveis-critério e preditores) e casos extremos multivariados (pela distância de Mahalanobis), que foram excluídos do conjunto $(n=12)$. A amostra de 215 casos é a amostra final considerada nas análises, após a exclusão desses casos potencialmente influentes (a amostra inicial era composta por 246 casos). As variáveis foram ainda inspecionadas visualmente quanto à sua distribuição, sendo que nenhuma apresentou assimetria expressiva (os valores de assimetria, em módulo, foram inferiores a $0,60)$. Por fim, a linearidade entre as variáveis-critério e os preditores foi examinada com regressões lineares simples, tomando cada preditor isoladamente. A inspeção dos gráficos dos resíduos padronizados em função dos valores preditos não sugeriu a existência de relações não lineares.

Testes $t$ ou análise de variância foram utilizados para investigar diferenças entre escores dos fatores do ITC, de necessidade financeira e de comportamentos de busca de emprego dos estudantes categorizados de acordo com o valor de carreira prioritário e de acordo com a avaliação do mercado de trabalho. Nas comparações entre grupos, foi previamente verificado o pressuposto da homogeneidade de variâncias (testes de Levene), não sendo identificada nenhuma violação da homogeneidade.

\section{Resultados}

Nas análises de regressão, tanto para a variável-critério atividades de busca de emprego quanto para contatos de rede social para busca de emprego, foram incluídos como preditores apenas as variáveis que apresentaram correlações bivariadas significativas $(p<0,05)$ com as respectivas variáveis-critério. Isso foi feito para evitar a inclusão de preditores não relevantes nas análises (as correlações das variáveis não incluídas com as variáveis-critério foram inferiores a 0,10$)$. No caso das atividades de busca de emprego, os preditores incluídos foram controle $(r=-0,19, p=0,006) \mathrm{e}$ necessidade financeira $(r=0,27, p<0,001)$. Já para contatos 
Tabela 1. Análises de regressão para atividades de busca de emprego e contatos de rede social para busca de emprego

\begin{tabular}{|c|c|c|c|c|c|}
\hline Variável / Preditores & B & Erro padrão & $\mathrm{IC}^{* * *}$ & Beta & Sig. \\
\hline \multicolumn{6}{|l|}{$\mathrm{ABE}^{*}$} \\
\hline Necessidade financeira & 0,68 & 0,18 & 0,$32 ; 1,03$ & 0,25 & $<0,001$ \\
\hline Controle & $-0,28$ & 0,13 & $-0,54 ;-0,02$ & $-0,14$ & 0,037 \\
\hline \multicolumn{6}{|l|}{$\mathrm{CRBE}^{* *}$} \\
\hline Controle & $-0,24$ & 0,11 & $-0,45 ;-0,04$ & $-0,15$ & 0,022 \\
\hline Necessidade financeira & 0,49 & 0,14 & 0,$20 ; 0,77$ & 0,22 & 0,001 \\
\hline Apoio social & 0,45 & 0,17 & 0,$12 ; 0,78$ & 0,17 & 0,008 \\
\hline
\end{tabular}

de rede social para busca de emprego, os preditores foram apoio social $(r=0,15, p=0,025)$, controle $(r=-0,19, p=$ $0,006)$ e necessidade financeira $(r=0,24, p<0,001)$. Nas análises de regressão, optou-se pelo método de regressão simultânea, a fim de identificar as contribuições específicas de cada variável.

A análise de regressão para a variável atividade de busca de emprego (sem contatos de rede social) mostrou que, em conjunto, controle e necessidade financeira explicaram $8,5 \%$ ( $\mathrm{R}^{2}$ ajustado) da variância $[\mathrm{F}(2,212)=10,95, p<0,001]$. Já a análise de regressão para a variável dependente frequência de contatos de rede social para busca de emprego revelou que, em conjunto, necessidade financeira, apoio social e controle explicaram $9,7 \%\left(\mathrm{R}^{2}\right.$ ajustado) da variância $[\mathrm{F}(3,211)=8,61$, $p<0,001]$. A Tabela 1 exibe os resultados dessas análises. Salienta-se que o sinal negativo do valor relativo ao preditor controle informa que quanto maior a externalidade do lócus de controle maior a atividade de busca de emprego.

Os participantes foram a seguir categorizados de acordo com as suas avaliações do mercado de trabalho na respectiva área profissional e comparados nas variáveis de atividades de busca de emprego, contatos de rede social para busca de emprego, necessidade financeira, motivação, autoeficácia, independência, apoio percebido e controle. Em virtude de alguns grupos terem tido poucos casos, a avaliação da situação do mercado foi reduzida a duas categorias: avaliação positiva (respostas muito, bom, razoável tendendo a bom) e negativa (respostas muito ruim, ruim, razoável tendendo a ruim). Testes $t$ revelaram diferenças estatisticamente significativas nas variáveis necessidade financeira, motivação, autoeficácia, lócus de controle e uma diferença marginalmente significativa para contatos de rede social de busca de emprego. A Tabela 2 apresenta os resultados dessas análises. Indivíduos que avaliaram o mercado de trabalho de um modo negativo apresentaram maiores níveis de necessidade financeira e menores de motivação, autoeficácia e controle, além de uma tendência a terem mais comportamentos de contatos de rede social para busca de emprego. Note-se que os tamanhos de efeito obtidos ( $d$ de Cohen) variaram de pequenos a médios.

Os participantes foram também categorizados de acordo com o valor de carreira colocado em primeiro lugar, e comparados em seus escores dos fatores do ITC, de necessidade

Tabela 2. Médias (desvios-padrão) e comparações de variáveis disposicionais, contextuais e busca de emprego conforme avaliação do mercado de trabalho

\begin{tabular}{|c|c|c|c|c|c|c|}
\hline & \multicolumn{4}{|c|}{ Avaliação do mercado } & \multirow[b]{3}{*}{$d^{* * *}$} & \multirow[b]{3}{*}{$p$} \\
\hline & \multicolumn{2}{|c|}{ Negativa $(n=73)$} & \multicolumn{2}{|c|}{ Positiva $(\mathrm{n}=142)$} & & \\
\hline & $M$ & $D P$ & $M$ & $D P$ & & \\
\hline Necessidade financeira & 6,82 & 2,34 & 5,70 & 2,41 & 0,47 & $<0,01$ \\
\hline Motivação & 15,67 & 2,78 & 16,56 & 2,56 & 0,34 & 0,02 \\
\hline Autoeficácia & 17,95 & 3,53 & 19,11 & 3,45 & 0,34 & 0,02 \\
\hline Independência & 13,18 & 2,76 & 13,35 & 2,85 & 0,06 & 0,68 \\
\hline Apoio social & 17,45 & 2,10 & 17,45 & 2,04 & 0,00 & 0,99 \\
\hline Lócus de controle & 15,95 & 3,46 & 17,48 & 3,18 & 0,47 & $<0,01$ \\
\hline $\mathrm{CRBE}^{*}$ & 16,19 & 5,58 & 14,73 & 5,12 & 0,28 & 0,06 \\
\hline $\mathrm{ABE}^{* *}$ & 16,37 & 7,05 & 15,44 & 6,44 & 0,14 & 0,33 \\
\hline
\end{tabular}

${ }^{*}$ Contatos de Rede Social para Busca de Emprego

${ }^{* * *}$ Atividades de Busca de Emprego (sem contatos de rede social)

${ }^{* * *} d=$ tamanho do efeito (Cohen) 
Tabela 3. Médias (desvios-padrão) de variáveis disposicionais, contextuais e busca de emprego em cada valor de carreira.

\begin{tabular}{|c|c|c|c|c|c|c|c|c|}
\hline & \multicolumn{8}{|c|}{ Valores de carreira } \\
\hline & \multicolumn{2}{|c|}{ Fazer o que mais gosto } & \multicolumn{2}{|c|}{ Estabilidade no emprego } & \multicolumn{2}{|c|}{ Ganhos financeiros elevados } & \multicolumn{2}{|c|}{ Liderança } \\
\hline & $M$ & $D P$ & $M$ & $D P$ & $M$ & $D P$ & $M$ & $D P$ \\
\hline Motivação & 16,84 & 2,51 & 15,65 & 3,00 & 15,30 & 2,32 & 17,33 & 2,17 \\
\hline Autoeficácia & 20,00 & 3,46 & 17,43 & 3,88 & 18,40 & 3,04 & 18,83 & 3,20 \\
\hline Independência & 13,07 & 2,68 & 13,04 & 2,92 & 13,68 & 2,46 & 14,61 & 2,99 \\
\hline Apoio social & 17,69 & 1,94 & 17,67 & 2,17 & 17,43 & 2,06 & 17,50 & 1,98 \\
\hline Controle & 18,11 & 2,74 & 15,09 & 3,72 & 17,00 & 3,16 & 16,22 & 3,08 \\
\hline Neces. financeiras & 5,78 & 2,17 & 6,98 & 2,32 & 5,50 & 2,66 & 6,06 & 2,10 \\
\hline CRBE* & 14,93 & 4,62 & 16,00 & 5,34 & 15,33 & 5,93 & 17,00 & 5,37 \\
\hline $\mathrm{ABE}^{* *}$ & 14,38 & 5,84 & 17,72 & 7,22 & 14,55 & 6,33 & 18,33 & 5,35 \\
\hline
\end{tabular}

*Contatos de Rede Social para Busca de Emprego

**Atividades de Busca de Emprego (sem contatos de rede social)

financeira e das medidas de comportamentos de busca de emprego. Nessas análises foram considerados apenas quatro subgrupos, compostos por mais de 15 participantes, conforme o valor prioritário de carreira: "fazer o que mais gosto" ( $\mathrm{n}=55)$, "estabilidade no emprego" $(\mathrm{n}=46)$, "ganhos financeiros elevados" (n=40) e "liderança" (n=18). Esse recorte justifica-se na medida em que se evita a comparação de muitos grupos com tamanhos pequenos, o que pode gerar resultados menos confiáveis, ao mesmo tempo em que se dá destaque àqueles valores de carreira considerados mais salientes nessa amostra.

Análises de variância revelaram diferenças entre os grupos nos escores de motivação $[\mathrm{F}(3,155)=4,56, p=0,004$, $\left.\eta^{2}=0,081\right]$, autoeficácia $\left[\mathrm{F}(3,155)=4,73, p=0,003, \eta^{2}=\right.$ $0,084]$, controle $\left[\mathrm{F}(3,155)=7,74, p<0,001, \eta^{2}=0,130\right]$, necessidade financeira $\left[\mathrm{F}(3,155)=3,37, p=0,020, \eta^{2}=0,061\right]$, e frequência de atividade de busca de emprego (ABE) $[\mathrm{F}(3$, $\left.155)=3,79, p=0,012, \eta^{2}=0,068\right]$. A Tabela 3 apresenta os resultados descritivos destas análises.

Análises post hoc (testes de Tukey) revelaram que indivíduos que priorizaram "estabilidade de emprego" demonstraram ter mais necessidade financeira do que aqueles que elegeram como prioridade "ganhos financeiros elevados"; e mais atividades de busca de emprego (ABE) em comparação com participantes que priorizaram "fazer o que mais gosto". Por outro lado, indivíduos cujo valor principal era "estabilidade no emprego" apresentaram escores mais baixos em autoeficácia (comparado ao grupo "fazer o que mais gosto") e controle (comparado aos grupos "fazer o que mais gosto" e "ganhos financeiros elevados"). Por fim, o grupo que priorizou "ganhos financeiros elevados" apresentou escores mais baixos em motivação do que os grupos cujas prioridades eram "fazer o que mais gosto" e "liderança".

\section{Discussão}

As análises de regressão indicaram baixo poder preditivo das variáveis psicológicas investigadas e da necessidade financeira sobre comportamentos de busca de emprego. Verificou-se ainda que o lócus de controle externo esteve associado com busca de emprego, contrariando expectativas teóricas de que a internalidade seja a condição mais favorável para o enfrentamento de transições de carreira em geral. Não obstante, tal resultado é consistente com os achados de van Hooft e Crossley (2008), que encontraram uma relação positiva entre lócus de controle externo para a busca de emprego e comportamentos efetivos de busca. Considerando as variáveis dependentes em estudo, relacionadas a comportamentos de busca de emprego, é possível que a externalidade esteja associada à consciência de que o sucesso nessa busca depende das decisões de empregadores e das condições do mercado de trabalho, o que pode estimular um movimento de busca de oportunidades por meio do investimento na exploração do ambiente e de relacionamentos sociais.

Nesse sentido, autores como La Rosa (1991) e Abbad e Meneses (2004) consideram inadequada a rotulação negativa do indivíduo com altos escores em externalidade, uma vez que fatores do ambiente social (como mercado de trabalho, oferta de emprego) não são controláveis pelo indivíduo e afetam seus níveis de externalidade. Isso pode ser verdadeiro na condição do buscador de emprego contemporâneo. Portanto, sugere-se que o lócus de controle seja uma característica considerada em contexto, a fim de que sua contribuição para o ajustamento e bem-estar de pessoas em diferentes circunstâncias possa ser adequadamente esclarecida. Essa perspectiva foi apoiada por Pasquali et al. (1998), por exemplo, que propõem que o construto lócus de controle, ao contrário de um traço de personalidade, seria mais bem compreendido como um estado disposicional do indivíduo que se modifica de acordo com a situação. Enfim, pode-se entender a associação entre externalidade e comportamentos de busca de emprego como o resultado da capacidade do indivíduo perceber que as oportunidades de emprego e o sucesso na busca de emprego estão, em grande parte, na dependência de outras pessoas e do próprio mercado de trabalho, e também do cultivo de redes sociais e do senso de oportunidade do buscador.

A categorização dos participantes de acordo com sua prioridade de valor na busca de emprego revelou a importância dos valores de carreira para o entendimento do tema. Aqueles que priorizaram "estabilidade no emprego" mostraram maior necessidade financeira do que indivíduos com a 
prioridade "ganhos financeiros elevados" e maior frequência de atividade de busca de emprego (ABE) do que indivíduos com a prioridade "fazer o que mais gosto". Além disso, esses mesmos participantes apresentaram escores baixos em aspectos de autoeficácia em comparação ao grupo "fazer o que mais gosto" e lócus de controle mais externo em comparação aos grupos "ganhos financeiros elevados" e "fazer o que mais gosto". Pode-se supor que a pressão financeira, mais frequentemente associada à condição sócio-econômica desfavorável, resulte na fragilização de fatores disposicionais importantes para o enfrentamento de transições de carreira e na tendência do indivíduo abrir mão de fazer o que gosta ou mesmo de procurar posições mais rentáveis (geralmente de maior risco) e se preocupar mais com a estabilidade do vínculo empregatício.

Em contraste, sujeitos que priorizaram "fazer o que mais gosto" informaram menor necessidade financeira, maior senso de autoeficácia em relação à transição para o mercado de trabalho, assim como maior internalidade de controle sobre esse processo (em comparação aos que valorizam estabilidade). Estes resultados sugerem que, nesta amostra de universitários, aqueles voltados para aspectos intrínsecos da atividade profissional (preocupados com realização pessoal) são também mais autoconfiantes, atribuem a causalidade de suas conquistas ou insucessos a si mesmos, e também tendem a estar sob menor pressão financeira. Deve-se ter cautela, contudo, para não se desconsiderar os efeitos que a experiência de busca de emprego pode ter sobre o indivíduo. Assim, é possível também que os estudantes que priorizam "fazer o que mais gosto" possuam uma representação idealizada e otimista do processo de transição para o mercado de trabalho, decorrente de seu menor envolvimento em atividades de busca de emprego (ao menos em comparação com o grupo que prefere estabilidade). Talvez os valores prioritários dos sujeitos mudem na medida em que procuram trabalho e não conseguem colocação profissional, fazendo com que a pressão financeira aumente e a motivação e confiança diminuam, como consequência de resultados negativos na busca de emprego. Essas são interpretações a serem investigadas em pesquisas futuras.

Por outro lado, a prioridade "estabilidade no emprego", que pode ser considerada uma motivação extrínseca para a busca de emprego, foi associada a maior frequência de atividades de busca de emprego (ABE) em comparação à priorização de aspectos intrínsecos do papel de trabalho (fazer o que gosto). Tendo em vista que a pressão financeira foi associada à busca por estabilidade no emprego e à fragilização de alguns fatores disposicionais (lócus de controle e autoeficácia), pode-se colocar em questão a qualidade destas atividades de busca de emprego, pois tal como os participantes do estudo de Peres, Silva e Carvalho (2003), estes jovens profissionais podem ter reduzido seus níveis de aspiração em termos da realização de valores mais intrínsecos para dar conta de suas necessidades financeiras prementes.

Portanto, para compreender estes resultados, deve-se levar em consideração a diferença entre valores situacionais e centrais. A prioridade dada à "estabilidade no emprego" por $21,4 \%$ dos participantes pode ser interpretada em muitos casos como uma resposta à condição situacional da maior necessidade financeira associada a esses indivíduos, sendo esse um valor situacional ou periférico e não algo central para suas identidades como trabalhadores. Sendo assim, é possível que a prioridade dada à estabilidade no emprego mude com mais facilidade, em resposta a novas contingências ambientais e situacionais.

A necessidade financeira também se mostrou associada à avaliação do mercado de trabalho, na qual uma percepção negativa do mercado está associada a maior necessidade financeira. Por outro lado, indivíduos com percepção desfavorável do mercado obtiveram escores mais elevados de contatos de rede social para busca de emprego (CRBE), embora se deva ter em mente que essa diferença foi marginalmente significativa do ponto de vista estatístico. Portanto, observa-se novamente uma tendência de associação entre condições situacionais desfavoráveis, na percepção dos participantes, e maior intensidade de comportamentos de busca de emprego. Adiciona-se a esse quadro a externalidade do lócus de controle, associada a uma avaliação negativa do mercado, e também à maior frequência de comportamentos de busca de emprego e à busca por estabilidade.

Enfim, o conjunto dos resultados sugere que uma percepção desfavorável do mercado de trabalho, a maior pressão financeira, a preocupação com estabilidade no emprego e a externalidade do lócus de controle convergem para um conjunto inter-relacionado de fatores que também inclui uma maior intensidade de comportamentos de busca de emprego. Por outro lado, uma percepção mais favorável do mercado de trabalho, menor necessidade financeira, internalidade de lócus de controle, valores de realização pessoal (fazer o que se gosta), e escores mais elevados de autoeficácia são fatores que convergem e se articulam com uma menor intensidade de comportamentos de busca de emprego.

Esses resultados corroboram tendências observadas nos estudos de Neiva (1993, 1995, 1996). Entre os universitários estudados pela autora, aqueles com uma visão negativa do mercado aparentavam estar mais decididos sobre suas carreiras e estimaram menor tempo para o início da atividade profissional. Por outro lado, mostraram-se mais ansiosos e menos motivados. Portanto, considerando os resultados da presente pesquisa, algumas interpretações, questões e hipóteses podem ser levantadas. Interpreta-se que a associação entre maior necessidade financeira e uma visão negativa do mercado possa reduzir sentimentos de autoconfiança e controle; e a valorização da estabilidade no emprego adquira prioridade nesse contexto percebido como desfavorável. Sendo assim, a intensidade de comportamentos de busca de emprego em muitos casos pode ser a expressão de sentimentos de urgência, da redução de níveis de aspiração relacionados a metas de emprego, e de estratégias impulsivas de inserção profissional, processos que não levam em consideração metas de desenvolvimento pessoal através do trabalho. Desse modo, questiona-se a qualidade desses comportamentos de busca de emprego e seus possíveis resultados, pois se sabe da carência de um planejamento de carreira adequado entre universitários, que frequentemente não mostram clareza quanto a interesses e projetos de vida (Teixeira \& Gomes, 2004). Porém, é importante salientar que estas são interpretações que não podem ser derivadas diretamente dos resultados deste estudo, uma vez que se trata de uma pesquisa de corte transversal e correlacional. Recomenda-se que pesquisas 
futuras, num delineamento longitudinal, incluam a avaliação dos resultados de comportamentos de busca de emprego tanto em termos dos consequentes da busca (ofertas de emprego, entrevistas, rapidez de contratação) quanto em termos das características do emprego alcançado (status, adequação aos interesses, satisfação, intenção de permanência). Sugere-se que estes delineamentos controlem variáveis como a diversidade de cursos de graduação e suas respectivas condições mais objetivas de mercado de trabalho em cada região geográfica. Ainda, faz-se necessário ampliar as investigações relacionadas à variável lócus de controle para que possa ser mais bem esclarecido o seu papel na transição da universidade para o mercado de trabalho. Por fim, deve-se considerar que os tamanhos dos efeitos obtidos neste estudo, sejam os percentuais de variância explicada ou as diferenças observadas, foram pequenos ou no máximo médios, o que indica que devem existir outras variáveis, não incluídas nesta pesquisa, que podem contribuir para a explicação dos comportamentos de busca de emprego.

Por fim, os resultados apontaram aspectos a serem observados na compreensão e intervenção sobre processos de transição da universidade para o mercado de trabalho. Destaca-se, entre esses, a importância dos valores de carreira e recomenda-se que tais valores sejam objeto de avaliação e reflexão em programas de preparação para busca de emprego.

\section{Referências}

Abbad, G., \& Meneses, P. P. N. (2004). Locus de controle: validação de uma escala em situação de treinamento. Estudos de Psicologia, 9(3), 441-450.

Albert, K. A., \& Luzzo, D. A. (1999). The role of perceived barriers in career development: A social cognitive perspective. Journal of Counseling and Development, 77, 431-436.

Chen, D. J. Q, \& Lim, V. K. G. (2012). Strength in adversity: The influence of psychological capital on job search. Journal of Organizational Behavior, 33, 811-839.

Coetzee, M. \& Schreuder, A. M. G. (2008). A multi-cultural investigation of students' career anchors at a South African higher education institution. SA Journal of Labour Relations, 32(2), 45-65.

Coetzee, M., \& Esterhuizen, K. (2010). Psychological career resources and coping resources of the young unemployed African graduate: an exploratory study. SA Journal of Industrial Psychology, 36(1), DOI: 10.4102/sajip.v36i1.868

Heppner, M. J., Multon, K. D., \& Johnston, J. A. (1994). Assessing psychological resources during career change: Development of the Career Transitions Inventory. Journal of Vocational Behavior, 44, 55-74.

Kanfer, R., Wanberg, C. R., \& Kantrowitz, T. M. (2001). Job search and employment: A personality motivation analysis and metaanalytic review. Journal of Applied Psychology, 86, 837-855.

Kim, N. (2005). Organizational interventions influencing employee career development preferred by different career success orientations. International Journal of Training and Development, 9, 47-61.

La Rosa, J. (1991). Lócus de controle: uma escala de avaliação. Psicologia: Teoria e Pesquisa, 7(3), 327-344.
Lent, R. W., Brown, S. D., \& Hackett, G. (2000). Contextual supports and barriers to career choice: A social cognitive analysis. Journal of Counseling Psychology, 47, 36-49.

Luthans, F., Youssef, C. M., \& Avolio, B. (2007). Psychological capital: Developing the human competitive edge. New York, NY: Oxford University Press.

Neiva, K. M. C. (1993). Effets psychologiques des contraintes du marché de l'emploi sur la motivation et l'anxiété des étudiants brésiliens en fin d'études universitaires. L'orientation Scolaire et Professionelle, 22, 273-282.

Neiva, K. M. C. (1995). Le comportment des étudiants brésiliens en fin d'études universitaires selon leurs débouchés professionnels: une application du modèle Lisrel. Revue Européenne de Psychologie Appliquée, 45, 103-108.

Neiva, K. M. C. (1996). Fim dos estudos universitários: efeitos das dificuldades do mercado de trabalho na representação do futuro profissional e no estabelecimento de projetos pós-universitários dos estudantes. Psicologia USP, 7, 203-224.

Pasquali, L., Alves, A. R., \& Pereira, M. A. M. (1998). Escala de lócus de controle ELCO/TELEBRÁS. Psicologia: Reflexão $e$ Crítica, 11(2), 363-378.

Peres, R. S., Silva, J. A., \& Carvalho, A. M. R. (2003). Um olhar psicológico acerca do desemprego e da precariedade das relações de trabalho. Psicologia: Teoria e Prática, 5(1), 97-110.

Saks, A. M. (2005). Job search success: a review and integrations of the predictors, behaviors and outcomes. In S. D. Brown, \& R. W. Lent (Eds.), Career development and counseling: Putting theory and research to work (pp. 155-179). Hoboken, NJ: Wiley \& Sons.

Schein, E. (1990). Career stress in changing times: some final observations. Prevention in Human Services, 8(1), 251-261.

Sharabi, M., \& Harpaz, I. (2009). Core and peripheral values: an over time analysis of work values in Israel. Journal of Human Values, 15, 153-166.

Slebarska, K., Moser, K., \& Gunnesch-Luca, G. (2009). Unemployment, social support, individual resources and job search behavior. Journal of Employment Counseling, 46, 159-170.

Super, D. E., \& Sverko, B. (Eds.) (1995). Life roles, values and careers. São Francisco, CA: Jossey-Bass.

Šverko, B., Galić, Z., Seršić, D. M., Galešić, M. (2008). Unemployed people in search for a job: Does job-seeking behavior matters that much? Journal of Vocational Behavior, 72, 415-428.

Teixeira, M. A. P. (2002). A experiência de transição entre a universidade e o mercado de trabalho na adultez jovem. Tese de Doutorado não publicada, Universidade Federal do Rio Grande do Sul. Porto Alegre.

Teixeira, M. A. P., \& Gomes, W. B. (2004). Estou me formando... e agora?: Reflexões e perspectivas de jovens formandos universitários. Revista Brasileira de Orientação Profissional, 5(1), 47-62.

van Hooft, E. A. J., \& Crossley, C. D. (2008). The joint role of locus of control and perceived financial need in job search. International Journal of Selection and Assessment, 16, 258-271.

Vinokur A. D., \& Schul, Y. (2002). The web of coping resources and pathways to reemployment following a job loss. Journal of Occupational Health Psychology, 7, 68-83. 
Wanberg, C. R., Watt, J. D., \& Rumsey, D. J. (1996). Individuals without jobs: An empirical study of job seeking behavior and reemployment. Journal of Applied Psychology, 81, 76-87.

Wanberg, C. R., Kanfer, R., \& Rotundo, M. (1999). Unemployed individuals: Motives, job-search competencies, and job search constrains as predictors of job seeking and reemployment. Journal of Applied Psychology, 84, 897-910.

Wanberg, C. R., Kanfer, R., \& Banas, J. T. (2000). Predictors and outcomes of networking intensity among unemployed job seekers. Journal of Applied Psychology, 85, 491-503.

Wanberg, C. R., Hough, L. M., \& Song, Z. (2002). Predictive validity of multidisciplinary model of reemployment success. Journal of Applied Psychology, 87, 1100-1120.
Zikic, J., \& Saks, A. M. (2009). Job search and social cognitive theory: The role of career-relevant activities. Journal of Vocational Behavior, 74, 117-127.

Recebido em 13.11.2010

Primeira decisão editorial em 27.07.2012

Versão final em 09.03.2013

Aceito em 13.08.2013 